\title{
Autodirección, habilidades de pensamiento y rendimiento académico en estudiantes normalistas
}

\section{Self-direction, thinking skills and academic performance in Teachers' College students}

DOI:10.32870/dse.v0i19.492

\author{
Marco Antonio Escamilla Pérez* \\ Yolanda Heredia Escorza**
}

\begin{abstract}
Resumen
Las habilidades cognitivas y metacognitivas son esenciales en la adquisición de conocimiento. En ambientes educativos es importante conocer el grado de desarrollo de estas habilidades y determinar si están relacionadas con el desempeño académico de los estudiantes. Esta investigación busca establecer la relación entre desarrollo de habilidades de pensamiento, la autodirección y el desempeño académico, con un diseño cuantitativo, transversal, ex post facto, llevado a cabo con estudiantes normalistas de primero y último año de una Escuela Normal de México. Para la recolección de datos se utilizaron tres herramientas: los promedios generales de los alumnos; el CIPA+ para determinar el perfil autodirigido, y una prueba de destrezas de pensamiento. Los datos se analizaron de acuerdo al coeficiente de correlación de Pearson, pareados en combinaciones de grado y perfil. Los resultados obtenidos sugieren correlación, aunque débil, entre las variables.
\end{abstract}

Palabras clave: autodirección - habilidades del pensamiento - rendimiento académico.

\section{Abstract}

Cognitive and metacognitive abilities are essential for knowledge acquisition. In educative environments, knowing the level of development of these abilities is important, as well as determining whether these abilities are related to students' academic performance. This paper shows the results of research on the relationship among the development of thinking abilities, self-direction and academic performance. The research used a quantitative, transversal, ex post facto design, and took place in a Teachers' College in Mexico with first and last grade students. The three tools used to collect the data were the students' general averages; the CIPA+ to determine the self-directed

*Candidato a Maestro en Educación. Disciplina: Filosofía y Educación. Docente frente a grupo en la Centenaria y Benemérita Escuela Normal del Estado de Querétaro (CBENEQ), México. Línea de investigación: Desarrollo Cognitivo. marescami@gmail.com

** Doctora en Innovación Educativa. Disciplina: Innovación educativa. Docente Investigador en el Instituto Tecnológico de Estudios Superiores de Monterrey. México. Línea de Investigación: Desempeño Académico.yheredia@itesm.mx 
profile, and a thinking skills test. All data were analyzed using the Person correlation coefficient, pairing them in combinations of degree and profile. The results suggest a correlation, albeit weak, among the variables.

Key words: self-direction - thinking skill - academic performance.

\section{Introducción}

El estudio del desempeño académico y los factores que pueden afectarlo no es nuevo. Desde la década de 1960 se han realizado estudios que relacionan el desempeño académico con diversos factores, tanto personales como familiares y escolares. Mucha de la investigación se ha desarrollado para la educación básica, en tanto que se localizan menos investigaciones en el caso de la educacion superior. Además, cada uno de los estudios presenta un contexto particular y una aproximación distinta a su estudio. Por ejemplo, Quereda, Díaz y Nicolás (2008) se basan en las teorías de motivación-logro y de autoeficacia para explicar el desempeño académico de estudiantes en la materia de Marketing en una universidad española. En otro estudio, se distingue cómo los antecedentes socioeconómicos de aspirantes a una escuela normal podían predecir el rendimiento académico de los candidatos aceptados y de los no aceptados (Quijada, Noriega y Matus, 2014).

El estudio de los factores que pueden incidir en el desempeño académico es amplio y variado. Actualmente se consideran tres factores íntimamente relacionados con este, los personales, los de orden social y los institucionales. Dentro de la dimensión personal, los factores cognitivos y de autorregulación se consideran de relevancia, pues "un aprendiz efectivo es aquel que llega a ser consciente de las relaciones funcionales entre sus patrones de pensamiento y de acción (estrategias) y los resultados socio-ambientales" (Corno y Mandinach, 1983; Corno y Rohrkemper, 1985; citados por Ramírez, Clavero y Salguero, 2003: 413).

El rendimiento académico puede no reflejar el nivel de esfuerzo, ni el grado de habilidad de los estudiantes, "habilidad y esfuerzo no son lo mismo" (Edel Navarro, 2003: 1). Un estudiante con altas habilidades podría esforzarse poco y, aún así, conseguir el mismo rendimiento académico que un alumno con menor grado de desarrollo de habilidades, pero con una mayor inversión de recursos.

¿De qué depende que algunos alumnos tengan éxito académico y otros no? Mientras algunos alumnos buscan el éxito escolar, otros buscan solo aprender, sin importar las implicaciones académicas (Quereda et al., 2008). Los estudiantes tienen sus propias metas, más allá de lo que se espera de ellos académicamente.

Es importante, entonces, conocer el grado de desarrollo de las habilidades de los alumnos y si estas guardan relación con los resultados académicos. Todo, de forma que, más adelante, se 
puedan implementar programas que ayuden a los alumnos a desarrollar, ya sea sus habilidades de pensamiento o sus habilidades de autodirección, si es necesario.

Se considera que en educación superior los estudiantes sean capaces de acceder al conocimiento de forma autónoma y que generen o gestionen sus propios recursos para ello. Si estas habilidades están relacionadas con su desempeño académico, en algún sentido podría predecirse su desempeño profesional.

En este momento, cuando se evalúa de manera constante el desempeño de los docentes en México, tener información sobre el rendimiento académico y los factores que intervienen en la formación de los futuros docentes puede ser una herramienta útil para determinar posibles rutas de acción.

En ambientes educativos, el desempeño académico expresado en términos cuantitativos se ha convertido en un referente para la promoción. Algunos de estos ejemplos se pueden observar en las convocatorias para la obtención de becas escolares o para el ingreso a programas académicos superiores. Incluso, cuando se habla de calidad educativa, el rendimiento académico es un indicador a observar (Garbanzo Vargas, 2007).

El rendimiento académico es un instrumento que ayuda a dar cuenta del avance de los estudiantes en las diferentes áreas disciplinares. Sin embargo, su definición es aún complicada, debido a que no se ha alcanzado un consenso particular. Barbera et al. (2012), consideran que el rendimiento académico se ha definido en función de los marcos referenciales desde cada uno de los enfoques usados para su estudio.

Se puede entender el rendimiento académico como el resultado de una acción en específico, esto es, como la nota alcanzada, o bien como el proceso que se utilizó para llegar a tal resultado, o como una combinación de ambos. Por ello, el rendimiento académico se relaciona con diferentes factores. Ugartetxea (2001) relaciona el desempeño de los estudiantes con su contexto, motivaciones y habilidades. Conocer la relación que existe entre el desempeño de los estudiantes y los factores que lo afectan puede ayudar a identificar qué aspectos habrán de tenerse en cuenta para el desarrollo de actividades escolares (Montero Rojas, Villalobos Palma et al., 2007).

Barbera et al. (2012) comentan que hay una cantidad considerable de estudios que hacen referencia al concepto de desempeño académico, identificado, indistintamente, como: rendimiento escolar, rendimiento académico, desempeño escolar, aptitud escolar y logro académico. Se entiende que las diferencias de nomenclatura no afectan el concepto en general. Sin embargo, sus aproximaciones operacionales sí lo hacen.

Siguiendo a Gimeno-Sacristán (1976), el rendimiento académico se entiende como la nota o calificación que los alumnos logran al final de un curso escolar. Para Gómez-Castro y Jiménez (1986; 2000, citados por Barbera et al., 2012: 53), el rendimiento académico es "el nivel de conocimientos y capacidades escolares exhibidas por estudiantes en un área o materia determinada expresadas mediante cualquier procedimiento de evaluación". Mientras que para De la Orden, 
Oliveros Mafokozi y González (2001, citados por Barbera et al., 2012: 53), el rendimiento académico es "la valoración de los logros obtenidos relacionándolos con lo invertido en dinero, tiempo y esfuerzo".

Otra definición de rendimiento académico la ofrece Jiménez (2000, citado por Edel Navarro, 2003: 2), quien lo entiende como el "nivel de conocimientos demostrado en un área o materia comparado con la norma de edad y nivel académico". En esta definición el rendimiento académico estaría en función de tres elementos: conocimiento, edad y grado escolar.

En la definición anterior, el rendimiento académico se relaciona con una variable cuantitativa en algún punto del ciclo escolar. El rendimiento académico se puede concebir como las calificaciones por materia o el promedio general de un ciclo o de un número de ciclos escolares juntos. Estas perspectivas sobre el desempeño académico han llevado a que las notas finales sean los indicadores más usados para dar cuenta de él. Esta visión ha sido criticada pues se ha considerado que un número no caracteriza el avance real de los alumnos, ni la calidad de los productos, ni la profundidad del conocimiento (Ayán y Díaz, 2011).

Fortaleza (1975, citado por González, 1988: 32) define el rendimiento académico como "la productividad del sujeto, el producto final de la aplicación de su esfuerzo, matizado por sus actividades, rasgos y la percepción más o menos correcta de los cometidos asignados". El rendimiento académico no se considera, solamente, un resultado, sino también el proceso para llegar a él.

El rendimiento académico estaría en función de una serie de actividades realizadas para llegar a la concreción de un producto y no solo en el producto. Esto implica la valoración del proceso y del resultado. El éxito o fracaso escolar, es decir, el desempeño académico favorable o desfavorable está en función de su definición y su operacionalización.

El rendimiento académico se considera la suma de varios factores. Por un lado, la nota final de una actividad, asignatura o ciclo escolar. Por otro, lo que el alumno puede hacer en función de las habilidades desarrolladas y el conjunto de conocimientos adquiridos. Aquí, el rendimiento académico es considerado como el promedio total de las evaluaciones particulares por asignatura de cada estudiante. En esta investigación el término que se utilizó fue el de rendimiento académico.

\section{Factores que afectan el rendimiento académico}

A pesar de que el rendimiento académico en ocasiones es reducido a un número, es necesario analizar los factores que lo afectan. Dichos factores se pueden generar en aspectos propios del estudiante (internos) o en aspectos que intervienen en el contexto del estudiante (externos). Si se atiende a los aspectos internos, se hablaría de cuestiones cognitivas o emocionales; si, por otro lado, se atiende a los aspectos externos, se hablaría de aspectos sociales, familiares o escolares (Garbanzo Vargas, 2007). 
Como ya se ha mencionado, existen tres factores principales que afectan el rendimiento académico: $a$ ) determinantes personales; $b$ ) determinantes sociales, y c) determinantes institucionales. En este estudio se abordaron solo los factores personales $y$, específicamente, la autorregulación y las habilidades cognitivas.

\section{Factores personales}

Los factores personales se entienden como los aspectos internos del individuo. Pueden ser de carácter cognitivo o emocional. La motivación de los estudiantes es un factor que puede incidir en el rendimiento académico. Un estudiante con creencias altas sobre su autoeficacia, con expectativas altas de éxito y una elevada motivación intrínseca, esto es, que valore el aprendizaje y tenga metas claras de aprendizaje, posee mayor oportunidad de éxito (Harter, 1986; Pintrich, 1989; Schunk, 1989; Dweck, 1986; Stipek, 1988, citados por Ramírez, Clavero y Salguero, 2003).

Por otro lado, las habilidades cognitivas y metacognitivas de los estudiantes son también factores importantes y determinantes en el desempeño académico. En este sentido, algunos investigadores han encontrado una relación positiva entre las estrategias de autorregulación y las habilidades cognitivas. Las primeras están relacionadas con el uso de estrategias para potenciar el aprendizaje y dirigirlo. Las segundas son los procesamientos propios de la información (Valle, Martínez, Cabanach, Pérez y Rosário, 2009).

\section{Autorregulación y habilidades cognitivas}

\section{Autorregulación}

La autorregulación o autodirección del aprendizaje deriva de la andragogía (Knowles et al., 2001, citado por Heredia y Sánchez, 2013), esto es, la forma en que los adultos aprenden. Uno de los principales autores sobre la autorregulación es Zimmerman, quien la define como: "la generación de pensamientos, sentimientos y creencias que la persona realiza para alcanzar sus metas" (2000, citado por Heredia y Sánchez, 2013: 236).

Pintrich (2000, citado por Martín-Cuadrado, 2011: 136), por otro lado, ha contribuido también al estudio de la autorregulación en el aprendizaje. Él la define como "un proceso activo y constructivo por el cual el estudiante establece sus propios objetivos de aprendizaje, procurando monitorear, regular y controlar sus pensamientos, su motivación y su comportamiento de acuerdo a dichos objetivos".

En cuanto a su medición, en 2008, por ejemplo, Cázares y Aceves (citados por Heredia y Sánchez, 2013), confirmaron la validez interna y la capacidad predictiva de su Cuestionario de Indagación del Perfil Autodirigido Aumentado (CIPA+), el cual consta de 50 reactivos divididos en cinco componentes: a) planeación y selección de estrategias; $b$ ) autorregulación y motivación; c) independencia y autonomía; d) uso de la experiencia y conciencia crítica; y e) interdependencia y valor social. En este caso, para Cázares (2008) la autodirección está definida por el grado de desarrollo de los cinco componentes mencionados en su test. 
Rosário et al. (2014) encontraron que los conceptos de autorregulación y autodirección del aprendizaje eran usados indistintamente y que, con ello, no daban cuenta de un concepto base que clarificara sus características generales. Sin embargo, ellos mismos concluyeron que todos los conceptos de autorregulación coincidían en que el sujeto era un agente activo de su propio aprendizaje.

Esto coincide, en principio, con una de las características que propone Knowles (1975, citado por Martín-Cuadrado, 2011) sobre el aprendizaje autónomo, el cual considera que el individuo tome la iniciativa en su propio proceso de aprendizaje. Además, el aprendiz autoevalúa sus resultados, tanto del aprendizaje final como del proceso para llegar a él.

Esto también sugiere que los resultados en el aprendizaje autorregulado se pueden ver desde dos perspectivas: como metas de aprendizaje y como metas de rendimiento. Según algunas investigaciones, los estudiantes con metas académicas tienden a hacer uso de estrategias cognitivas profundas tales como la observación y la autoobservación, así como presentar altos niveles en la creencia de autoeficacia (Kaplan, Middleton, Urdan y Midgley, 2002; Pintrich, 2000, citados por Montalvo y Torres, 2004).

En cuanto a las metas de rendimiento, los estudios no han sido concluyentes pues no se han podido integrar los resultados de forma empírica (Elliot, 1999, citado por Montalvo y Torres, 2004). Sin embargo, se ha propuesto que los estudiantes que no persiguen metas de rendimiento, sino solamente metas de aprendizaje, pueden actuar contra sus intereses o poner en riesgo oportunidades académicas (Dweck, 1986, citado por Montalvo y Torres, 2004).

Esto quiere decir que hay varios elementos a tomar en cuenta cuando se habla de autorregulación en el aprendizaje. Sobre todo, en la parte de los objetivos que cada estudiante persigue y las habilidades con las que cuenta para lograrlo pues la autorregulación tiene elementos que se relacionan con las habilidades cognitivas.

\section{Habilidades cognitivas}

Las habilidades cognitivas se entienden como destrezas y procesos mentales usados para realizar actividades y adquirir conocimiento, mediante la codificación y recuperación de información (Reed, 2007, citado por Ramos, 2010). Las habilidades cognitivas se dividen en básicas y superiores. Las básicas son: atención, obtención y recuperación de información, organización, análisis, transformación y evaluación. En tanto que las superiores son: solución de problemas, toma de decisiones, pensamiento crítico y pensamiento creativo (Ramos, 2010).

Sin embargo, existen también las habilidades del pensamiento que, si bien no se entienden como cognitivas desde el planteamiento de Ramos (2010), sí son parte del proceso del pensamiento. De acuerdo a este autor, las habilidades cognitivas se entienden como competencias cognitivas. Todas ellas, divididas en cinco grupos (Swartz y Parks, 1994, citados por Sanz (2011):

Diálo pos sobre Educación 
pensamiento comprensivo, pensamiento crítico, pensamiento creativo, toma de decisiones y solución de problemas.

Por otro lado, para Amestoy de Sánchez (2002: 12), las habilidades del pensamiento parten del conocimiento procedimental. El cual se entiende como "el conjunto ordenado de pasos o acciones que acompañan a un acto mental o una actividad motora". Se sigue entonces que al llevar a la práctica estos procedimientos, se generan las habilidades del pensamiento. Estos procesos se dividen en: básicos, de razonamiento, superiores y metaprocesos.

Estas posturas hacen difícil una taxonomía única de las habilidades del pensamiento (Limón y Carretero, 1995). Por ello, Limón y Carretero proponen cuatro tipos de habilidades: de razonamiento, de solución de problemas, estrategias de aprendizaje y metacognitivas. Lo que se puede observar es que todos incluyen en las habilidades metacognitivas las características propias de la autorregulación. Además, infieren que "el desarrollo de todas estas habilidades tendría como meta conseguir que el propio individuo aprenda cómo piensa, cómo puede mejorar sus habilidades intelectuales o cómo puede sacar el mejor rendimiento a sus habilidades" (Limón y Carretero, 1995: 4).

Según Niño (2014: 87), las habilidades del pensamiento son "capacidades que permiten construir y organizar el conocimiento para poder aplicarlo con eficacia en las situaciones de la vida". En otras palabras, las habilidades del pensamiento se relacionan con los procesos cognitivos involucrados en la adquisición de conocimiento y su recuperación para la solución de problemas, ya sean de carácter procedimental o semántico, como propone Amestoy de Sánchez (2002).

Algunas investigaciones sugieren que el rendimiento académico se relaciona con el desarrollo de habilidades del pensamiento. Esto se puede ver en el bajo rendimiento académico de los estudiantes que muestran deficiencias en el uso del pensamiento formal, crítico y creativo (Arons, 1979; Whimbey y Lochhead, 1986; Montealegre, 1992; Raths et al., 1997; Reyes, 2004, citados por Navarro 2004).

Se entiende entonces que si el aprendiz desarrolla habilidades del pensamiento, tanto básicas como superiores, su rendimiento académico puede mejorar. Como sugiere Coral (2014), las habilidades del pensamiento fungen como mediadoras del aprendizaje y, por lo tanto, como potenciadoras del rendimiento académico. Si el estudiante desarrolla sus competencias cognitivas en función de solucionar problemas relacionados con las actividades escolares, el rendimiento se verá favorecido en cuanto a la consecución de las metas académicas.

Como las habilidades del pensamiento son parte de las habilidades cognitivas, en este estudio se entenderán ambas como habilidades del pensamiento. Todas en su función de mediadoras del aprendizaje. De aquí su conexión con la autorregulación, pues la autorregulación está relacionada con aspectos de índole personal, y la metacognición es uno de ellos (Zimmerman y Rocha, 1984, 1987; Zimmerman y Martínez-Pons, 1986; 1988; 1992, citados por Ramírez et al., 2003). 
Las habilidades del pensamiento y la autorregulación son fundamentales para el desarrollo de habilidades para la resolución de problemas (Navarro, 2004). Siguiendo esto, el desempeño académico se vería beneficiado si se toma en cuenta que lo que se busca es que el estudiante sea capaz de presentar productos finales adecuados que den cuenta de su proceso de aprendizaje, de su grado de avance y profundidad de conocimiento de su área.

Por último, Valle et al. (2009), encontraron que el uso de habilidades del pensamiento, en conjunto con estrategias de autorregulación, influían en el rendimiento académico de estudiantes en secundaria. Esto es, en cuanto mayor era el uso de ambas, mayor era el rendimiento observado. Por otro lado, González (1996) concluye que la no activación de las habilidades del pensamiento de orden superior y la falta de conciencia de estas habilidades influyen en el control y supervisión de los procesos de aprendizaje del alumno y, en consecuencia, en su desempeño.

En el último año de formación, los estudiantes normalistas se enfrentan a la actividad de desarrollar un proyecto de intervención o una tesis para acceder al grado académico. Sin embargo, este proceso no les resulta fácil. Se ha observado que una parte mayoritaria de los alumnos no muestran, en la realización del documento, las competencias de análisis y reflexión, así como las de autorregulación en dicho proceso.

A pesar de lo observado, no se han aplicado instrumentos que determinen con eficacia los grados de autodirección y de desarrollo de habilidades de pensamiento presentadas por los estudiantes. Por otro lado, los estudiantes, en general, egresan con promedios altos en sus boletas finales. De aquí la inquietud por cuestionar si las calificaciones reflejan los avances en aspectos de desarrollo de competencias cognitivas y de autorregulación esperadas como parte del perfil de egreso de los estudiantes.

De acuerdo con lo anterior, la pregunta que guió esta investigación fue: ¿existe una relación entre el desempeño académico, la autodirección y las habilidades del pensamiento en los estudiantes normalistas, tanto de nuevo ingreso como de último año?

\section{Metodología}

La investigación tiene un enfoque cuantitativo y se buscó dar cuenta del grado de desarrollo de las variables en un momento determinado y sin haberlas manipulado en forma directa. Por ello, se decidió que la investigación siguiera un diseño ex post-facto de corte transversal (Hernández, Fernández, Baptista y Casas, 2010).

El estudio se realizó en una escuela normal de México, encargada de la preparación de docentes de educación básica. La institución cuenta con una población total de 439 alumnos, de los cuales 382 son mujeres y 57 hombres, distribuidos en 135 alumnos en Educación Primaria, 120 alumnos en Educación Preescolar, 115 alumnos en Educación Especial, 18 alumnos en Educación Secundaria y 51 alumnos en Maestría. Las edades de los alumnos de licenciatura

Diólo@os Sobre Educación año 10 | número 19 | julio-diciembre 2019 | ISSN 2007-2171 
están entre 18 y 28 años, y los estudiantes de maestría están entre 23 y 45 años. Los estudiantes provienen tanto de poblaciones rurales como de la zona urbana.

Para la aplicación de los instrumentos se selecionó a los estudiantes del Plan 2012 y, específicamente, a los alumnos de primero y último años de las licenciaturas de educación preescolar y primaria. La muestra se considera de tipo no aleatoria, estratificada, ya que se aplicaron los instrumentos a todos los alumnos de los dos grupos de último año (1 grupo de educación preescolar, 1 grupo de educación primaria) y a todos los alumnos de los dos grupos de primer semestre (1 grupo de educación preescolar y 1 grupo de educación primaria).

El número de participantes fue de 26 en educación preescolar de último año, todas mujeres, 32 en educación primaria de último año, siendo 8 hombres y 24 mujeres, 35 en educación preescolar de primer año, siendo 1 hombre y 34 mujeres, y 35 en educación primaria de primer año, siendo 8 hombres y 27 mujeres. La totalidad de participantes fue de 128 estudiantes, de los cuales 111 eran mujeres y 17 hombres, cuyas edades van de los 18 a los 35 años.

Para colectar la información se usaron dos tests: el Cuestionario de Indagación del Perfil Autodirigido Aumentado (CIPA+) de Cázares y Aceves (2008) y la Prueba de destrezas del pensamiento de Lago, Echeverría y Moreno (2007).

El CIPA+ está basado en el CIPA original de Cázares, el cual tenía 41 reactivos divididos en cuatro componentes: $a$ ) planeación y selección de estrategias; $b$ ) autorregulación y motivación; c) independencia y autonomía; y d) uso de la experiencia y conciencia crítica (Aceves, 2008). El CIPA original es un cuestionario con escala Likert de cinco opciones, construido para medir el perfil autodirigido de los estudiantes.

Sin embargo, el CIPA+ considera nueve ítems adicionales al original de Cázares, que incluyó un nuevo componente: la interdependencia y valor social (Aceves, 2008). Este componente está en función de competencias sociales y de interacción a través de medios físicos y virtuales. El CIPA+ está conformado por un cuestionario con escala Likert de cinco opciones con 50 preguntas. El cuestionario se presenta por escrito y los resultados se evalúan de acuerdo con lo que Aceves (2008) presenta en su estudio.

La prueba de destrezas del pensamiento fue tomado y adaptado del elaborado por Lago, Echeverría y Moreno (2007). Esta prueba está diseñada para"medir o evaluar la capacidad de los alumnos y alumnas en el manejo de las habilidades y destrezas" del pensamiento (Lago, Echeverría y Moreno, 2007). El diseño y elaboración de esta prueba está basada en la Prueba de Virginia Shipman (o prueba de New Jersey). Específicamente, esta prueba se origina a partir de la versión mexicana, elaborada por Eugenio Echeverría.

La intención de este test está dirigida a evaluar el grado de desarrollo de las habilidades de pensamiento. Lago, Echeverría y Moreno (2007) consideran que no es tan importante conocer el puntaje final de aciertos y errores, sino el saber las coincidencias de aciertos y errores dentro de un tipo de pensamiento. Sin embargo, para fines de esta investigación, sí se tomó el número 
total de aciertos y fallos en la prueba, con la intención de correlacionar un alto, un medio o un bajo nivel de desarrollo de las habilidades del pensamiento con el desempeño académico y el perfil de autodirección del alumno.

Por último, para medir el desempeño académico se tomó el promedio general de cada estudiante de último año desde el primero hasta el sexto semestre (apenas concluido). Mientras que, para medir el desempeño de los estudiantes de primer año, se tomaron los promedios generales de bachillerato. Para hacer una prueba comparativa, se tomaron también los promedios generales de bachillerato de los alumnos que cursan el último año.

\section{Datos generales de identificación}

En la tabla 1 se presentan los datos de género y el número de los participantes por grupos y en total.

Tabla 1. Género y número de los participantes por grupo

\begin{tabular}{|c|c|c|c|c|c|c|c|}
\hline \multirow[t]{2}{*}{ Licenciatura } & \multicolumn{2}{|c|}{ 1er. semestre } & \multicolumn{2}{|c|}{ 70. semestre } & \multicolumn{2}{|c|}{ Total x género } & \multirow{2}{*}{$\frac{\text { Total }}{\mathrm{H} / \mathrm{M}}$} \\
\hline & $\mathrm{H}$ & $\mathrm{M}$ & $\mathrm{H}$ & $\mathrm{M}$ & $\mathrm{H}$ & $\mathrm{M}$ & \\
\hline Preescolar & 1 & 34 & 0 & 26 & 1 & 60 & 61 \\
\hline Primaria & 8 & 27 & 8 & 24 & 16 & 51 & 67 \\
\hline Total por género & 9 & 61 & 8 & 50 & 17 & 111 & 128 \\
\hline Total por semestres & \multicolumn{2}{|c|}{70} & \multicolumn{2}{|c|}{58} & & & \\
\hline
\end{tabular}

Como se puede observar, hay una mayor cantidad de participantes del género femenino. En la Licenciatura en Educación Preescolar es donde más mujeres hay (60 en total). Sin embargo, en primaria se observa una relación aproximada de 3 mujeres por cada hombre. En total, la relación de participantes es de 6.5 mujeres por cada hombre.

En la tabla 2 se observan las edades de los participantes, tanto por licenciatura como por grado.

Tabla 2. Edades de los participantes

\begin{tabular}{|l|c|c|c|c|c|}
\hline & \multicolumn{2}{|c|}{ Preescolar } & \multicolumn{2}{c|}{ Primaria } & $\begin{array}{c}\text { Total por } \\
\text { participantes }\end{array}$ \\
\hline & 1er. semestre & $7^{\mathbf{0}}$ semestre & 1er. semestre & $7^{\circ}$ semestre & 20 \\
\hline Promedio & 19 & 22 & 19 & 23 & 18 \\
\hline Moda & 18 & 21 & 18 & 21 & 20 \\
\hline Mediana & 19 & 21 & 18 & 22 & 35 \\
\hline Máxima & 26 & 31 & 26 & 35 & 18 \\
\hline Mínima & 18 & 20 & 18 & 21 & \\
\hline
\end{tabular}


Las edades de los participantes sugieren que la mayoría de ellos han seguido un curso convencional en sus estudios, pasando de un grado a otro sin interrupción. Esto, con excepción de algunos casos en los que se observan edades máximas de 26 y 35 años. Sin embargo, estos son solo tres casos (dos para la edad de 26 años y uno para la edad de 35 años) en la totalidad de la muestra.

\section{Desarrollo}

Se presentaron cartas solicitando el permiso de la institución para llevar a cabo la investigación, así como el permiso de los participantes para acceder a su información académica. La información se recopiló a partir de los promedios generales de cada uno de los participantes. Esta información se vació a una tabla de Excel para su análisis.

Para llevar a cabo la aplicación de los instrumentos, se convocó a cada uno de los grupos en un horario específico por la mañana. Se les dieron las instrucciones para responder los instrumentos y no se les restringió el tiempo de entrega. Primero se aplicó el CIPA+ y unos minutos después, siguiendo el protocolo de aplicación, se realizó la prueba de destrezas o habilidades del pensamiento.

La información fue descargada a tablas de Excel para su análisis mediante la correlación de las variables, usando el coeficiente de Pearson. Esto se hizo en varias etapas. Como primera etapa se correlacionaron los promedios generales con los resultados del CIPA+. Después se correlacionaron los promedios generales con los resultados de la prueba de destrezas o habilidades. Por último, se correlacionaron los resultados del CIPA+ con los de la prueba de destrezas o habilidades de pensamiento, buscando encontrar alguna diferencia entre alumnos de primero y último grado.

\section{Resultados}

La incógnita inicial de esta investigación fue si existía correlación entre la autodirección, el desarrollo de las habilidades del pensamiento y el desempeño académico. La conformación de los grupos seleccionados para el estudio, permite una forma de análisis tanto en conjunto como separada.

\section{Resultados del test sobre habilidades del pensamiento}

El test de habilidades del pensamiento se aplicó a todos los participantes. Los resultados se presentan de forma general, por grados y de acuerdo a los estilos de pensamiento y los tipos de habilidades que se evalúan en la prueba. 
Tabla 3. Resultados generales del test de Habilidades del Pensamiento (HDP)

\begin{tabular}{|l|c|c|c|c|c|c|}
\hline \multirow{2}{*}{ Valoración } & \multicolumn{2}{|c|}{ Participantes de primer año } & Participantes de último año & \multicolumn{2}{c|}{ Total de participantes } \\
\cline { 2 - 7 } & $\begin{array}{c}\text { Número de } \\
\text { participantes }\end{array}$ & Porcentaje & $\begin{array}{c}\text { Número de } \\
\text { participantes }\end{array}$ & Porcentaje & $\begin{array}{c}\text { Número de } \\
\text { participantes }\end{array}$ & Porcentaje \\
\hline Insuficiente & 6 & $9 \%$ & 5 & $9 \%$ & 11 & $9 \%$ \\
\hline Suficiente & 33 & $47 \%$ & 27 & $47 \%$ & 60 & $47 \%$ \\
\hline Bueno & 25 & $36 \%$ & 21 & $36 \%$ & 46 & $36 \%$ \\
\hline Muy bueno & 5 & $7 \%$ & 5 & $9 \%$ & 10 & $8 \%$ \\
\hline Excelente & 1 & $1 \%$ & 0 & $0 \%$ & 1 & $1 \%$ \\
\hline
\end{tabular}

Los resultados generales del test de HDP se muestran de acuerdo al número de participantes por año; de igual forma los porcentajes. Es decir, 9\% de los participantes que cursan el primer año de su carrera obtuvieron una valoración insuficiente en el test, es decir, una calificación menor a 60. Así, la valoración "insuficiente" equivale a menos de $60 \%$ de respuestas correctas, "suficiente" equivale a una valoración entre $60 \%$ y $70 \%$ de respuestas correctas, "bueno" equivale a una valoración entre $71 \%$ y $80 \%$ de respuestas correctas, "muy bueno" equivale a una valoración entre $81 \%$ y $90 \%$ de respuestas correctas y "excelente" equivale a una valoración entre $91 \%$ y $100 \%$ de respuestas correctas.

Se puede ver que hay una paridad entre los estudiantes de primero y último años en los resultados generales del test. En cuanto al porcentaje de alumnos por muestra, en las valoraciones de insuficiente, suficiente y bueno, los resultados son similares. Sin embargo, en las valoraciones "muy bueno" $y$ "excelente" hay una diferencia mínima, destacando el hecho de que el único resultado con valoración de "excelente" fue obtenido por un alumno de primer año.

El desempeño de los estudiantes de último año (véase tabla 9) está dentro de un rango de "muy bueno" a "excelente". Sin embargo, los resultados del test de HDP indican que $47 \%$ de los participantes de último año obtuvieron un resultado de "suficiente" y $36 \%$ de "bueno". Solo $9 \%$ de los participantes de último año obtuvieron un resultado "muy bueno" en el test.

Esto se contrapone a lo que sugiere Coral (2014), pues se dice que las habilidades del pensamiento son potenciadoras del desempeño académico. Si bien los estudiantes de último año presentan un rendimiento académico alto, no es así en sus resultados en el test de habilidades del pensamiento.

Por otro lado, el que los participantes de primer año obtuvieran resultados similares a los participantes de último año en el test de HDP, sugiere que las actividades de los cursos de la carrera no han influido en el desarrollo de las HDP de los participantes. Aunque esto no se puede afirmar como un hecho ya que el test no fue aplicado a los alumnos de último año al ingresar a la institución. Sin embargo, los resultados implican una paridad en el desarrollo de las habilidades de los participantes indistintamente de si son de primero o último años. 
Ahora, en la siguiente tabla se muestran los resultados del test en función del tipo de habilidades que mide el test.

Tabla 4. Resultados del test por tipo de HDP

\begin{tabular}{|c|c|c|c|c|c|c|}
\hline \multirow{2}{*}{ Tipo de HDP } & \multicolumn{2}{|c|}{$\begin{array}{c}\text { Participantes de primer } \\
\text { año }\end{array}$} & \multicolumn{2}{|c|}{$\begin{array}{c}\text { Participantes de último } \\
\text { año }\end{array}$} & \multicolumn{2}{|c|}{ Total de participantes } \\
\hline & Correctas & Incorrectas & Correctas & Incorrectas & Correctas & Incorrectas \\
\hline 1. Ambigüedad & $85 \%$ & $15 \%$ & $84 \%$ & $16 \%$ & $85 \%$ & $15 \%$ \\
\hline 2. Analogía & $66 \%$ & $34 \%$ & $72 \%$ & $28 \%$ & $69 \%$ & $31 \%$ \\
\hline 3. Buenas preguntas & $84 \%$ & $16 \%$ & $82 \%$ & $18 \%$ & $83 \%$ & $17 \%$ \\
\hline 4. Buenas razones & $85 \%$ & $15 \%$ & $82 \%$ & $18 \%$ & $84 \%$ & $16 \%$ \\
\hline 5. Contradicción & $67 \%$ & $33 \%$ & $59 \%$ & $41 \%$ & $64 \%$ & $36 \%$ \\
\hline $\begin{array}{l}\text { 6. Diferencias grado- } \\
\text { clase }\end{array}$ & $67 \%$ & $33 \%$ & $68 \%$ & $32 \%$ & $67 \%$ & $33 \%$ \\
\hline 7. Generalización & $51 \%$ & $49 \%$ & $59 \%$ & $41 \%$ & $55 \%$ & $45 \%$ \\
\hline $\begin{array}{l}\text { 8. Inferencia de supues- } \\
\text { tos }\end{array}$ & $74 \%$ & $26 \%$ & $63 \%$ & $37 \%$ & $69 \%$ & $31 \%$ \\
\hline 9. Inversión lógica & $63 \%$ & $37 \%$ & $57 \%$ & $43 \%$ & $61 \%$ & $39 \%$ \\
\hline 10. Normalización & $74 \%$ & $26 \%$ & $78 \%$ & $22 \%$ & $76 \%$ & $24 \%$ \\
\hline 11. Posibilidades lógicas & $93 \%$ & $7 \%$ & $95 \%$ & $5 \%$ & $94 \%$ & $6 \%$ \\
\hline $\begin{array}{l}\text { 12. Relaciones causa- } \\
\text { efecto }\end{array}$ & $85 \%$ & $15 \%$ & $79 \%$ & $21 \%$ & $82 \%$ & $18 \%$ \\
\hline $\begin{array}{l}\text { 13. Relaciones parte- } \\
\text { todo }\end{array}$ & $78 \%$ & $22 \%$ & $84 \%$ & $16 \%$ & $80 \%$ & $20 \%$ \\
\hline $\begin{array}{l}\text { 14. Relaciones reversi- } \\
\text { bles }\end{array}$ & $91 \%$ & $9 \%$ & $75 \%$ & $25 \%$ & $84 \%$ & $16 \%$ \\
\hline $\begin{array}{l}15 . \text { Relaciones transiti- } \\
\text { vas }\end{array}$ & $44 \%$ & $56 \%$ & $47 \%$ & $53 \%$ & $45 \%$ & $55 \%$ \\
\hline $\begin{array}{l}\text { 16. Silogismo: Ponendo } \\
\text { Ponens }\end{array}$ & $63 \%$ & $37 \%$ & $57 \%$ & $43 \%$ & $60 \%$ & $40 \%$ \\
\hline $\begin{array}{l}\text { 17. Silogismo: Tollendo } \\
\text { Tollens }\end{array}$ & $76 \%$ & $24 \%$ & $74 \%$ & $26 \%$ & $75 \%$ & $25 \%$ \\
\hline $\begin{array}{l}\text { 18. Silogismo: Falso Po- } \\
\text { nendo Tollens }\end{array}$ & $64 \%$ & $36 \%$ & $65 \%$ & $35 \%$ & $65 \%$ & $35 \%$ \\
\hline $\begin{array}{l}\text { 19. Silogismo: Falso To- } \\
\text { Ilendo Tollens }\end{array}$ & $67 \%$ & $33 \%$ & $72 \%$ & $28 \%$ & $70 \%$ & $30 \%$ \\
\hline 20. Traducción & $75 \%$ & $25 \%$ & $76 \%$ & $24 \%$ & $75 \%$ & $25 \%$ \\
\hline
\end{tabular}


Se puede observar que en las habilidades de "generalización" y "relaciones transitivas" menos de $60 \%$ de los participantes de primer año contestaron correctamente. Mientras que las habilidades en las que menos de $60 \%$ de los participantes de último año obtuvieron respuestas correctas fueron las de "contradicción", "generalización", "inversión lógica", "relaciones transitivas", "silogismo: ponendo ponens". Esto sugiere que, en términos generales, los participantes del primer año tienen un desarrollo mayor de las HDP que sus compañeros de último año. Esto puede predecir un mejor rendimiento académico durante su carrera de los participantes de primer año que el obtenido por los estudiantes de último año (Arons, 1979; Whimbey y Lochhead, 1986; Montealegre, 1992; Raths et. al., 1997; Reyes, 2004, citados por Navarro, 2004).

En la tabla 5 se pueden observar los resultados del test de HDP de acuerdo a los estilos de pensamiento que mide el test.

Tabla 5. Resultados del test por estilo de pensamiento

\begin{tabular}{|l|c|c|c|c|c|c|}
\hline \multirow{2}{*}{ Estilo de pensamiento } & \multicolumn{2}{|l|}{ Participantes de primer año } & $\begin{array}{c}\text { Participantes de últi- } \\
\text { mo año }\end{array}$ & \multicolumn{2}{l|}{ Total de participantes } \\
\cline { 2 - 7 } & Correctas & Incorrectas & Correctas & Incorrectas & Correctas & Incorrectas \\
\hline $\begin{array}{l}\text { 1. Razonamiento infor- } \\
\text { mal }\end{array}$ & $79 \%$ & $21 \%$ & $78 \%$ & $22 \%$ & $78 \%$ & $22 \%$ \\
\hline 2. Indagación & $84 \%$ & $16 \%$ & $82 \%$ & $18 \%$ & $83 \%$ & $17 \%$ \\
\hline $\begin{array}{l}\text { 3. Razonamiento de- } \\
\text { ductivo }\end{array}$ & $66 \%$ & $34 \%$ & $65 \%$ & $35 \%$ & $66 \%$ & $35 \%$ \\
\hline $\begin{array}{l}\text { 4. Razonamiento in- } \\
\text { ductivo }\end{array}$ & $51 \%$ & $49 \%$ & $59 \%$ & $41 \%$ & $55 \%$ & $45 \%$ \\
\hline $\begin{array}{l}\text { 5. Razonamiento con- } \\
\text { dicional o hipotético }\end{array}$ & $68 \%$ & $32 \%$ & $67 \%$ & $33 \%$ & $67 \%$ & $33 \%$ \\
\hline $\begin{array}{l}\text { 6. Interpretación y tra- } \\
\text { ducción }\end{array}$ & $75 \%$ & $25 \%$ & $76 \%$ & $24 \%$ & $75 \%$ & $25 \%$ \\
\hline
\end{tabular}

Se observa que, en términos generales, un mayor número de participantes contestó correctamente las preguntas relacionadas con la habilidad de "indagación". Por otro lado, el número menor de participantes con respuestas correctas se dio en la habilidad de "razonamiento inductivo". En cuanto a la habilidad de "razonamiento deductivo" y a la de "razonamiento condicional o hipotético", los resultados indican que un número similar de alumnos obtuvo respuestas correctas, $66 \%$ y $67 \%$. Sin embargo, no llegan a $70 \%$ de la muestra en ninguno de los dos casos. Algo a destacar cuando la media del promedio de los participantes de último año es de 9.12 (véase tabla 16). 


\section{Resultado del CIPA+}

El CIPA+ presenta cinco componentes a tomar en cuenta: 1) planeación y selección de estrategias; 2 ) autorregulación y motivación; 3) independencia y autonomía; 4) uso de la experiencia y la conciencia crítica; y 5) interdependencia y valor social. Además, determina un valor integrado de los cinco componentes en una escala inversa a los resultados que se determinan como bajo, insuficiente, moderado, muy bueno y óptimo. Por ello, se presentan primero los resultados en función de cada uno de los componentes (tabla 6) y, posteriormente, de forma integrada (tabla 7). Todo, considerando el grado que cursan los participantes.

Tabla 6. Resultados del CIPA+ por componente

\begin{tabular}{|c|c|c|c|c|c|c|c|c|c|c|}
\hline \multirow[b]{2}{*}{ Valoración } & \multicolumn{2}{|c|}{ Comp. 1} & \multicolumn{2}{|c|}{ Comp. 2} & \multicolumn{2}{|c|}{ Comp. 3} & \multicolumn{2}{|c|}{ Comp. 4} & \multicolumn{2}{|c|}{ Comp. 5} \\
\hline & $\begin{array}{l}\text { 1er. } \\
\text { año }\end{array}$ & $\begin{array}{l}\text { Últ. } \\
\text { año }\end{array}$ & $\begin{array}{l}\text { 1er. } \\
\text { año }\end{array}$ & $\begin{array}{l}\text { Últ. } \\
\text { año }\end{array}$ & $\begin{array}{l}\text { 1er. } \\
\text { año }\end{array}$ & $\begin{array}{l}\text { Últ. } \\
\text { año }\end{array}$ & $\begin{array}{l}\text { 1er. } \\
\text { año }\end{array}$ & $\begin{array}{l}\text { Últ. } \\
\text { año }\end{array}$ & $\begin{array}{l}\text { 1er. } \\
\text { año }\end{array}$ & $\begin{array}{l}\text { Últ. } \\
\text { año }\end{array}$ \\
\hline Bajo & $13 \%$ & $12 \%$ & $7 \%$ & $9 \%$ & $11 \%$ & $12 \%$ & $14 \%$ & $22 \%$ & $6 \%$ & $5 \%$ \\
\hline Insuficiente & $10 \%$ & $31 \%$ & $9 \%$ & $21 \%$ & $14 \%$ & $31 \%$ & $21 \%$ & $12 \%$ & $4 \%$ & $0 \%$ \\
\hline Moderado & $24 \%$ & $26 \%$ & $27 \%$ & $34 \%$ & $30 \%$ & $29 \%$ & $20 \%$ & $29 \%$ & $7 \%$ & $9 \%$ \\
\hline Muy bueno & $33 \%$ & $26 \%$ & $33 \%$ & $24 \%$ & $36 \%$ & $24 \%$ & $27 \%$ & $31 \%$ & $23 \%$ & $40 \%$ \\
\hline Óptimo & $20 \%$ & $5 \%$ & $24 \%$ & $12 \%$ & $9 \%$ & $3 \%$ & $17 \%$ & $5 \%$ & $60 \%$ & $47 \%$ \\
\hline
\end{tabular}

En estos resultados se destacan los porcentajes del componente 5: interdependencia y valor social. Como se recuerda, este es el componente que se añadió al CIPA original. Como se puede observar, hay un número mayor de participantes de primer año (60\%) con un resultado "óptimo" en el componente mencionado, en comparación con los de último año (solo 47\%). Esto puede sugerir una mayor conciencia del uso de la tecnología para fines académicos por parte de los participantes de primer año.

Por otro lado, los componentes 1, 2 y 3 muestran un número constante de participantes de primer año con un resultado valorado en "muy bueno", 33\%, 33\% y $36 \%$, respectivamente. Esto indica que hay un número constante de participantes de primer año que tienen una muy buena valoración de la planeación y selección de estrategias, la autorregulación y la motivación, y de la independencia y la autonomía.

En cuanto a los resultados integrados del CIPA+, en la tabla 7 se pueden observar los porcentajes de alumnos, tanto por grado que cursan como el total, en función de su valoración. 
Tabla 7. Resultados integrados del CIPA+

\begin{tabular}{|l|c|c|c|}
\hline \multicolumn{1}{|c|}{ Valoración } & $\begin{array}{c}\text { Participantes } \\
\text { de primer año }\end{array}$ & $\begin{array}{c}\text { Participantes } \\
\text { de último año }\end{array}$ & $\begin{array}{c}\text { Total de parti- } \\
\text { cipantes }\end{array}$ \\
\hline Bajo & $7 \%$ & $3 \%$ & $5 \%$ \\
\hline Insuficiente & $3 \%$ & $10 \%$ & $6 \%$ \\
\hline Moderado & $19 \%$ & $43 \%$ & $30 \%$ \\
\hline Muy bueno & $39 \%$ & $29 \%$ & $34 \%$ \\
\hline Óptimo & $33 \%$ & $14 \%$ & $24 \%$ \\
\hline
\end{tabular}

Como se puede observar, el número de participantes de primer año con resultados de valoración "óptimo" en el perfil autodirigido es mayor (33\%) al del número de participantes de último año (14\%) con la misma valoración. Además, el mayor número de participantes de último año se coloca en la valoración "moderado" del perfil autodirigido (43\%). Mientras que el mayor número de participantes de primer año se coloca en la valoración "muy bueno" del perfil autodirigido (39\%).

Atendiendo a las observaciones anteriores y siguiendo lo que menciona Navarro (2004), el desempeño académico se debe ver beneficiado en los participantes con altos índices de perfil autodirigido. Así como lo encontraron Valle et al. (2009) ) en estudiantes de secundaria.

\section{Promedios de los participantes}

Para dar cuenta del desempeño académico de los participantes, se usaron los promedios generales de ingreso a la licenciatura para los participantes de primer año y los promedios acumulados de los semestres para los participantes de último año. También se consideraron los promedios de ingreso de los participantes de último año, solo como referencia. En la tabla siguiente se pueden ver las tendencias de los promedios de los participantes.

Tabla 8. Comparativa estadística de los promedios de los participantes

\begin{tabular}{|l|c|c|c|}
\hline $\begin{array}{c}\text { Descripción de } \\
\text { los promedios de } \\
\text { los participantes }\end{array}$ & $\begin{array}{c}\text { Promedios de ingre- } \\
\text { so de los participan- } \\
\text { tes de primer año }\end{array}$ & $\begin{array}{c}\text { Promedios de ingre- } \\
\text { so de los participan- } \\
\text { tes de último año }\end{array}$ & $\begin{array}{c}\text { Promedios acumula- } \\
\text { dos de los participan- } \\
\text { tes de último año }\end{array}$ \\
\hline Media & 8.51 & 8.83 & 9.12 \\
\hline Moda & 8.40 & 8.80 & 9.30 \\
\hline Mediana & 8.40 & 8.80 & 9.20 \\
\hline Máximo & 9.70 & 9.70 & 9.90 \\
\hline Mínimo & 7.00 & 8.00 & 8.20 \\
\hline
\end{tabular}


Como se puede observar, las tendencias de los promedios de ingreso de los participantes de último año son un poco más altos que los de primero. Además, se observa una mejora en el desempeño, reflejada en los promedios acumulados durante la carrera en los participantes de último año. En cuanto a los participantes de primer año, se observa que el promedio mínimo es de 7.00 y el máximo de 9.70, una diferencia de 2.70 puntos. Habrá que tomar en cuenta esto pues, como menciona Dweck (1986, citado por Montalvo y Torres, 2004), hay estudiantes que persiguen metas de aprendizaje, más que de rendimiento, y eso puede actuar en su contra.

Por otro lado, si se toman en cuenta los resultados del test de HDP y las tendencias de los promedios de los participantes de último año, podría suceder lo contario. Es decir, que los participantes busquen metas de rendimiento y no necesariamente metas de aprendizaje o desarrollo.

La tabla 9 presenta la valoración de los promedios y el número de participantes que se encuentran dentro de los rangos presentados.

Tabla 9. Valoración de los promedios de los participantes

\begin{tabular}{|c|c|c|c|}
\hline $\begin{array}{c}\text { Rango de valo- } \\
\text { ración }\end{array}$ & $\begin{array}{c}\text { Participantes de primer } \\
\text { año con promedios de } \\
\text { ingreso }\end{array}$ & $\begin{array}{c}\text { Participantes de último } \\
\text { año con promedios de } \\
\text { ingreso }\end{array}$ & $\begin{array}{c}\text { Participantes de últi- } \\
\text { mo año con promedios } \\
\text { acumulados }\end{array}$ \\
\hline 7 a 7.90 & $24 \%$ & $0 \%$ & $0 \%$ \\
\hline 8 a 8.90 & $43 \%$ & $60 \%$ & $33 \%$ \\
\hline 9 a 9.90 & $33 \%$ & $40 \%$ & $67 \%$ \\
\hline
\end{tabular}

Varias investigaciones sugieren una relación entre el desempeño académico, la autorregulación y el desarrollo de las HDP (Valle et al., 2009; González,1996; Navarro 2004; Ramírez et al., 2003). Sin embargo, si se observa el número de participantes de último año dentro del rango de promedio acumulado de 9 a 9.99 (67\%), en comparación con el número de participantes del mismo grupo con resultados "óptimo" en el perfil autodirigido (14\%) y con el número de participantes con valoración "excelente" (0\%) o "muy bueno" (9\%) en los resultados generales del test de HDP, se sugiere una relación inexistente. Es decir, $67 \%$ de los participantes de último año tienen un promedio acumulado en su carrera que está dentro de un rango considerado "excelente", mientras que, el número de participantes del mismo grupo, con perfiles autodirigidos óptimos y con resultados en el test de HDP excelentes, es muy pobre.

Si se observan las tendencias en los promedios de los participantes de primer año en comparación son sus resultados del CIPA+, se puede encontrar una tendencia en el número de participantes dentro de los rangos "moderado", "muy bueno" y "óptimo" (19\%, 39\%, 33\%, respectivamente) que corresponderían a las tendencias del número de participantes dentro 
de los rangos de 7 a 7.90, 8 a 8.90 y 9 a 9.99 de promedio (24\%,43\%, 33\%, respectivamente). No así si se observan las tendencias del test de HDP y los promedios de ingreso.

\section{Coeficiente de Pearson}

Para conocer si existe relación entre el desempeño académico, el desarrollo de las habilidades del pensamiento y el grado de autorregulación que expresan los participantes, se usó el coeficiente de correlación de Pearson.

En la tabla 10 se pueden observar los resultados para las relaciones del CIPA+ con el promedio de los participantes, así como para el test de HDP y el promedio. El análisis de los resultados se hizo en dos partes, uno para los participantes de primer año y otro para los de último año. La razón de presentarlo así es que se usaron promedios de diferente clase para la correlación. Para los participantes de primer año se usaron los promedios de egreso de bachillerato, entendidos como los promedios de ingreso. Mientras que para los estudiantes de último año se usaron los promedios generales acumulados durante la carrera.

Tabla 10. Coeficiente de Pearson para los grupos de primer y último años

\begin{tabular}{|c|c|c|}
\hline \multicolumn{1}{|c|}{ Relación } & $\begin{array}{c}\text { Participantes } \\
\text { de primer año }\end{array}$ & $\begin{array}{c}\text { Participantes } \\
\text { de último año }\end{array}$ \\
\hline CIPA+ / Promedio & 0.0011 & -0.0737 \\
\hline HDP / Promedio & 0.1735 & 0.1158 \\
\hline
\end{tabular}

Cabe recordar que los resultados para el CIPA+ son inversos a la puntuación obtenida. Es decir, a mayor puntaje del CIPA+, menor el grado de perfil autodirigido. Por lo tanto, si el coeficiente de Pearson arroja un resultado negativo para la relación entre el CIPA+ y el promedio, este resultado se interpretaría de forma inversa, como una relación positiva.

Como se observa en la tabla 10, la correlación del CIPA+ y el promedio, para los participantes de primer año, es casi nula (0.0011 tiende a 0 ), al igual que para los participantes de último año (-0.0737, con tendencia a 0 ). Se puede decir que, el perfil autodirigido que expresan los participantes, no guarda relación con los promedios de ingreso, ni con los acumulados. En cuanto a la correlación que se obtiene de las variables HDP y promedio, en los dos casos se observa una correlación débil positiva $(0<0.17<1$ para los participantes de primer año y $0<0.11<1$ para los de último año).

Por otro lado, como los valores que se presentan son poco significativos, se decidió hacer el análisis de los resultados por licenciatura y por grado que se cursa. Esto es, se hizo un análisis de la relación por cada grupo de primero y último años. 
Tabla 11. Coeficiente de Pearson para los grupos de primer y último años por licenciatura

\begin{tabular}{|l|c|c|c|c|}
\hline & \multicolumn{2}{|c|}{ Lic. en Educación Preescolar } & \multicolumn{2}{c|}{ Lic. en Educación Primaria } \\
\multicolumn{1}{|c|}{ Relación } & Primer año & Último año & Primer año & Último año \\
\hline CIPA+ / Promedio & -0.3604 & -0.2751 & 0.068 & 0.0298 \\
\hline HDP / Promedio & 0.2378 & -0.012 & 0.0751 & 0.2931 \\
\hline
\end{tabular}

De acuerdo con los resultados de la tabla 11, se observa una correlación mayor entre las variables de autodirección y promedio para los grupos de la Licenciatura en Educación Preescolar (LEPRE). Se interpreta que para los participantes de primer año de LEPRE, la correlación es moderada positiva (recuérdese que los resultados de CIPA+ son inversos). Se observa la misma tendencia para los participantes de último año de LEPRE. Mientras que para los participantes de la Licenciatura en Educación Primaria (LEPRIM), la correlación es similar para los dos grupos, casi nula.

En cuanto a las variables HDP y promedio, se observa una correlación positiva moderada para los participantes de primer año de LEPRE, así como para los participantes de último año de LEPRIM. Sin embargo, no así para los participantes de último año de LEPRE, ni para los de primer año de LEPRIM.

Aunque los resultados no presentan una regularidad consistente, se puede decir que sí hay una correlación entre las variables de autodirección, desarrollo de habilidades de pensamiento y desempeño académico, como lo sugieren estudios previos (Navarro, 2004; Valle et al., 2009; González, 1996; Coral, 2014). Con esto, el objetivo general de la investigación: determinar si existe una relación entre el desempeño académico con el grado de autodirección y desarrollo de habilidades de pensamiento, mostrado por los estudiantes normalistas de nuevo ingreso (1er. semestre) y de último año (70 semestre), se ha cumplido.

Por otro lado, se ha determinado el grado de autodirección y el desarrollo de las habilidades de pensamiento de los participantes. Se conoció el promedio de los estudiantes como referente para determinar el desempeño académico. Por ello, se considera que, para futuras investigaciones, habría que profundizar en aspectos como la evaluación del desempeño en la institución y las técnicas de autorregulación usadas por los participantes.

\section{Referencias}

Aceves, N. (2008). Adaptación, confiabilidad y validez del Cuestionario de Indagación del Perfil Autodirigido (CIPA) y su evaluación en Adultos Jóvenes que pertenecen a la sociedad del conocimiento (Edición Única). México: ITESM. 
Amestoy de Sánchez, M. (2002). “La investigación sobre el desarrollo y la enseñanza de las habilidades de pensamiento". Revista Electrónica de Investigación Educativa, 4(1), 01-32.

Ayán, M. N. R. y M. Á. R. Díaz (2011). "Indicadores de rendimiento de estudiantes universitarios: calificaciones versus créditos acumulados". Revista de Educación, 355, 467-492.

Barbera, C. G., J. C. Niebla, K. D. López y M. L. Ortega (2012). “Rendimiento académico y factores asociados: aportaciones de algunas evaluaciones a gran escala". Bordón. Revista de Pedagogía, 64(2), 51-68.

Coral, A. L. (2014). “Desarrollo de habilidades de pensamiento y creatividad como potenciadores de aprendizaje. Revista Unimar, 30(1). http://www.umariana.edu.co/ojs-editorial/index. php/unimar/article/view/232

Edel Navarro, R. (2003). “El rendimiento académico: concepto, investigación y desarrollo. REICE: Revista Electrónica Iberoamericana sobre Calidad, Eficacia y Cambio en Educación. https://repositorio.uam.es/handle/10486/660693

Garbanzo Vargas, G. M. (2007). "Factores asociados al rendimiento académico en estudiantes universitarios, una reflexión desde la calidad de la educación superior pública". Revista Educación, 31(1), 43-63.

Gimeno-Sacristán, J. (1976). Autoconcepto, sociabilidad y rendimiento escolar. Madrid: Servicio de Publicaciones del MEC.

González, A. (1988). "Indicadores del rendimiento escolar: relación entre pruebas objetivas y calificaciones". Revista de Educación, 287, 31-54.

González, F. (1996). "Acerca de la metacognición". Paradigma, 14(1-2). https://www.researchgate.net/profile/Fredy Gonzalez5/publication/228811443 Acerca de la metacognicin/ links/54cf77ad0cf29ca810fe28cf.pdf

Heredia, Y. y A. L. Sánchez (2013). Teorías del aprendizaje en el contexto educativo. México: Editorial Digital del Tecnológico de Monterrey.

Hernández, R., C. Fernández, P. Baptista y M. de la L. Casas (2010). Metodología de la investigación. México: McGraw-Hill.

Lago, J. C., E. Echeverría y J. Moreno (2007). Manual para el manejo de la prueba de "Destrezas del Pensamiento". http://filosofiaparaninos.org/la-evaluacion-del-programa-de-filosofia-paraninos-en-entorno-multiculturales/

Limón, M. y M. Carretero (1995). “Aspectos evolutivos y cognitivos". Revista Cuadernos de Pedagogía. http://www.terras.edu.ar/biblioteca/6/TA Limon-Carretero 2 Unidad 5.pdf

Martín-Cuadrado, A. M. (2011). "Competencias del estudiante autorregulado y los estilos de aprendizaje". Journal of Learning Styles, 4(8). http://learningstyles.uvu.edu/index.php/jls/ article/view/68

Montalvo, F. T. y M. C. G. Torres (2004). “El aprendizaje autorregulado: presente y futuro de la investigación". Revista Electrónica de Investigación Psicoeducativa, 2(1), 1-34. 
Montero Rojas, E., J. Villalobos Palma et al. (2007). "Factores institucionales, pedagógicos, psicosociales y sociodemográficos asociados al rendimiento académico en la Universidad de Costa Rica: Un análisis multinivel". http://www.uv.es/relieve/v13n2/RELIEVEv13n2 5.htm

Niño, N. Y. G. (2014). “Desarrollo de habilidades de pensamiento a través de la lúdica:'Una experiencia significativa"'. Quaestiones Disputatae: temas en debate, 3(6). http://revistas.ustatunja.edu.co/index.php/qdisputatae/article/view/278

Quereda, P. F. P., J. C. Díaz y S. R. Nicolás (2008). “Antecedentes del rendimiento académico: aplicación a la docencia en marketing". Revista Española de Investigación de Marketing, 12(2), 7-24.

Quijada, A. I. Y., J. Á. V. Noriega y J. E. M. Matus (2014). “El proceso de admisión de las escuelas normales y los antecedentes socioeconómicos como predictores del rendimiento académico". Revista Intercontinental de Psicología y Educación, 16(2), 111-129.

Ramírez, M. I. H., F. H. Clavero y M. I. R. Salguero (2003). “Cognición-metacognición, motivación y rendimiento académico". Eúphoros, 6, 409-431.

Rosário, P., A. Pereira, J. Hógemann, A. R. Nunes, M. Figueiredo, J. C. Núñez y M. L. Gaeta (2014). "Autorregulación del aprendizaje: una revisión sistemática en revistas de la base SciELO". Universitas Psychologica, 13(2), 781-797.

Sanz, D. A. L. M. (2011). Competencias cognitivas en educación superior. Madrid: Narcea Editores. http://0-www.ebrary.com.millenium.itesm.mx

Ugartetxea, J. (2001).“Motivación y metacognición, más que una relación”. Relieve, 7(2-1). http:// www.uv.es/relieve/v7n2/RELIEVEv7n2 1.htm

Valle, A., S. R. Martínez, R. G. Cabanach, J. C. N. Pérez y P. Rosário (2009). “Diferencias en rendimiento académico según los niveles de las estrategias cognitivas y de las estrategias de autorregulación". Summa Psicológica UST, 6(2), 31-42. 